\title{
HUMAN RESOURCE E-LEAVE MANAGEMENT: A DECISION SUPPORT SYSTEM
}

\author{
Mitzi S. Fortich ${ }^{1}$ \\ mitzisfortich@su.edu.ph
}

\author{
Dave E. Marcial ${ }^{2}$ \\ demarcial@su.edu.ph
}

\begin{abstract}
The main purpose of the study was to develop a Human Resource e-Leave Management System for the university that will be more efficient and synchronized than the current manual system. In order to have an efficient and effective management of leave transactions, the web-based system was designed and implemented with modules on leave applications, leave balances monitoring, records management, administration, and install the business intelligence technique to aid in the decision making activities of the HRDM Officer and the Management. It offers streamlined operations, fair application of leave policies, introduction of more statistical reports and a more productive workforce. The development methods used were Process Modeling and UML diagrams. The tools and languages used in developing the system were Ajax, Adobe Flash and Flash Player, JavaScript, jQuery, HTML5 and CSS3 for the client-side coding and PHP for the server-side coding. MySQL was used for the database and XAMPP as the web server. The development environment was Eclipse Web Tools Platform, and the development framework was CodeIgniter. Structured questionnaires were used to conduct the Preliminary Survey, System Usability and Web Usability Evaluation. The main findings of this study revealed that the system is fully compliant with the standard System Usability Guidelines. Likewise, the Web Usability showed that the employees strongly agreed on the implementation of the system in order to have a quick response and access to information. The results of the Web Accessibility test also showed that the completed system is error-free and passed the standard guidelines for Web Accessibility.
\end{abstract}

Keywords: Information System, Management Information Systems, Human Resource Information Systems, Leave Management

\section{INTRODUCTION}

Human resource management is the organizational function that deals with issues related to people such as compensation, hiring, performance management, organization development, safety, wellness, benefits, employee motivation, communication, administration, and training (Heathfield, n.d.). Leave the management is one of the most important HR processes that consume a small but significant portion of managerial time. While managers are usually overloaded with projects and hunger for resources, approving subordinates' leaves is a tight rope walk. On one hand HR has to ensure compliance with leave policy and ensure availability of sufficient resources for business continuance; on the other hand, it has to improve employee satisfaction. Most people have witnessed bitter manager-employee relations on issues of leaves. Thus, leave management becomes an important strategic task for the organization.

\footnotetext{
${ }^{1}$ University Graduate Programs, Silliman University Hibbard Avenue, Dumaguete City, Negros Oriental

${ }^{2}$ College of Computer Studies, Silliman University Hibbard Avenue, Dumaguete City, Negros Oriental
} 
In the Philippines, the utilization of online leave management systems in schools and universities is not that widespread. Only a few institutions like the University of San Carlos in Cebu City - a sister school of Holy Name University - has incorporated a leave management module in its Information System (IS) since 2011. Holy Name University employs a total of 417 in their workforce. The employees are categorized into two significant groups i.e. the Faculty and the Administrative Personnel. Further, the Administrative Personnel is sub-divided into two: Non-Academic and the Academic Support Personnel. Currently, there are 271 faculty members from Grade School to Graduate level, 125 Non-academic personnel, and 21 Academic Support Personnel. For many years now, the school has been using an online system to do all the needed operations, but there are continuing issues between the external programmer and the institution. Hence, in 2012 an MIS group was formed to work on Holy Name University Integrated Information System (HNUIIS) geared to develop an overall information system of the university to replace the existing one. Now, the MIS team is developing the enrollment system and has not yet started on any administrative module such as the HRDM subsystem. Although the HRDM Officer has already expressed the need of its office for an online system to the MIS team, this has not been prioritized. When the proposal for an Online Employees' Leave Management System was brought to the University President, he immediately approved of the plan. The Human Resource e-Leave Management System will be a sub-module to the HRDMO system that has yet to be developed by the MIS team.

Human Resource e-Leave Management System for Holy Name University will give the school the opportunity to streamline communication between HRDMO and employees and facilitate simple yet efficient management of employee leaves. Leave management ensures that all leaves taken and leave requests are properly accounted for. Employees can apply, approve and view leave records without the hassle and delay of going through the admin staff. Further, this system allows them to determine their vacation availability quickly (from any point-intime), and request leave online. The system provides full audit trails of the employees' leave balances and plans. For the management, leave approvals no longer involve trails of paperwork. Moreover, it can be used to support strategic decision making, to evaluate programs or policies, or to support daily operating concerns.

This paper describes the development of an electronic leave management system for Holy Name University. It specifically presents the analysis, design and implementation of the proposed system. Further, this paper highlights the decision support mechanism of the leave management of the human resource of the school.

\section{SCOPE AND LIMITATIONS OF THE STUDY}

The online leave management system was designed, developed and implemented taking the distinction of the leave of absence policies, types of leaves and the leave management of the university. This system was designed using the same technologies and tools used by the MIS team to maintain consistency in design and minimize problems in programming and conflicts in implementation when integrated to the whole HNUIIS.

The HRDM Officer advised that the study shall not include Solo Parent Leave and the Leave of Absence with Pay (study leave) because the drafting of the policies of such leave types is still ongoing. Further, the Leave of Absence with Pay (study leave) is not considered as one of the regular leaves because it is under the HRD Scholarship Program. The scope of this project is limited to several processes: handling of employees' leave applications, managing leave balances, records management, administration, leave management. It will generate the reports such as leave trends of the company, employee availability, employee leave balance, leave rejection, leave acceptance, employees with "no leave in the academic year", and absence monitoring. 


\section{RELATED SYTEMS}

A feasibility conducted by Jayarathna (n.d.) presents the system of accumulating the personal information of the staff of the University of Colombo School of Computing currently done manually. Currently, attendance of the non-academic and contract staff uses finger print readers. The system dealt with Personal Information and Leave Management System, implemented only for use inside the intranet of the administrative branch of the university to ensure restricted user access. The system expects to get output and process leaves. Finally, the system has to generate reports such as leaves of contract employees monthly and leaves of academic staff monthly and annually that are given to the financial division of the university.

Some academic institutions already incorporate leave management module in their HRIS. These include Shepherd University in West Virginia, United States, University of Technology in Jamaica, and University of San Carlos (Philippines). At Shepherd University full-time classified and non-classified employees will use the online leave management system to request annual and sick leave and to check their leave balance. Supervisors will use the system to approve or disapprove leave requests for the employees who report to them. If a paper leave report is needed, then it may be printed one at any time. There are three types of reports that may be produced: 1) Leave Balance, 2) Status of Leave Requests, and 3) User Time Off Settings (Shepherd University, n.d.). University of Technology in Jamaica allows employees to submit leave request, submit work resumption, look up leave request, and cancel leave request. The supervisors are allowed to approve leave request, cancel approved leave request, and verify or deny work resumption. The HR can approve and deny leave request and adjust balances (University of Technology, n.d.). University of San Carlos in Cebu City started its leave management module as part of its Information System in 2011. The module only provides automation of the leave (sick leave, vacation leave and emergency leaves) processes resulting in a paperless system. The output is a text file for the Payroll Section (University of San Carlos, n.d.). These three systems focused only on the automation of the processes, and generation of reports from the transactions and do not integrate interactive and graphical reports that are the focus of Decision Support Systems like that of the proposed study. The reports will support the quality decision-making activities of the HRDMO and management of HNU.

\section{THE SYSTEM DEVELOPMENT}

\section{Functional Requirements}

This section contains the details of the processes of the different operations that are undertaken by the users of the system. There are four registered users of the system namely: the HRDM Officer, the HR Staff, the Approver who could be the Principal/Dean/Head of Office, and the employees. The following is a list of the functionalities of the system: Employee Records, Department Records, Apply for Leave, Approve/Deny/Cancel Leave Request, Adjust Leave Credits, Leave Transactions, Statistics and Reports, Leave Balance of all employees or for each employee per department or office, Personal Setting Module, Access to the system, and Export/Import Data.

\section{Non-Functional Requirements}

A non-functional requirement shows the operation of a system, rather than functional requirements that define specific behavior or functions. The following are the non-functional requirements of the system:

1. The system should be used with any web browser that supports the Canvas tag and the date picker. The Canvas tag is used to render the graphical results of the system and is supported in IE9, Firefox, Chrome, Safari, iOS Safari, Opera, Opera Mobile and Android browsers. It also can be viewed by most mobile browsers. 
2. The system should operate on available technology (e.g., Windows and Linux Server, Wireless and Wired Public Internet Access) provided by the university.

\section{Development Framework}

The development diagram of the proposed HR e-Leave Management System (Figure 1) illustrates how the system must be developed in terms of data providers, modules of the proposed system, processes, networks, connectivity, users and deliverables. The data providers are mainly the employees who submit their leave application online and the dean/principal/head either approves or rejects the application. The HRDM Officer and the HR Staff also perform a very valuable role in the system, especially in the administration modules and they are the recipient of the business analytics results. The system will generate reports for the Payroll Section, Planning Office, Vice President for Academic Affairs and Vice President for Administration Offices.

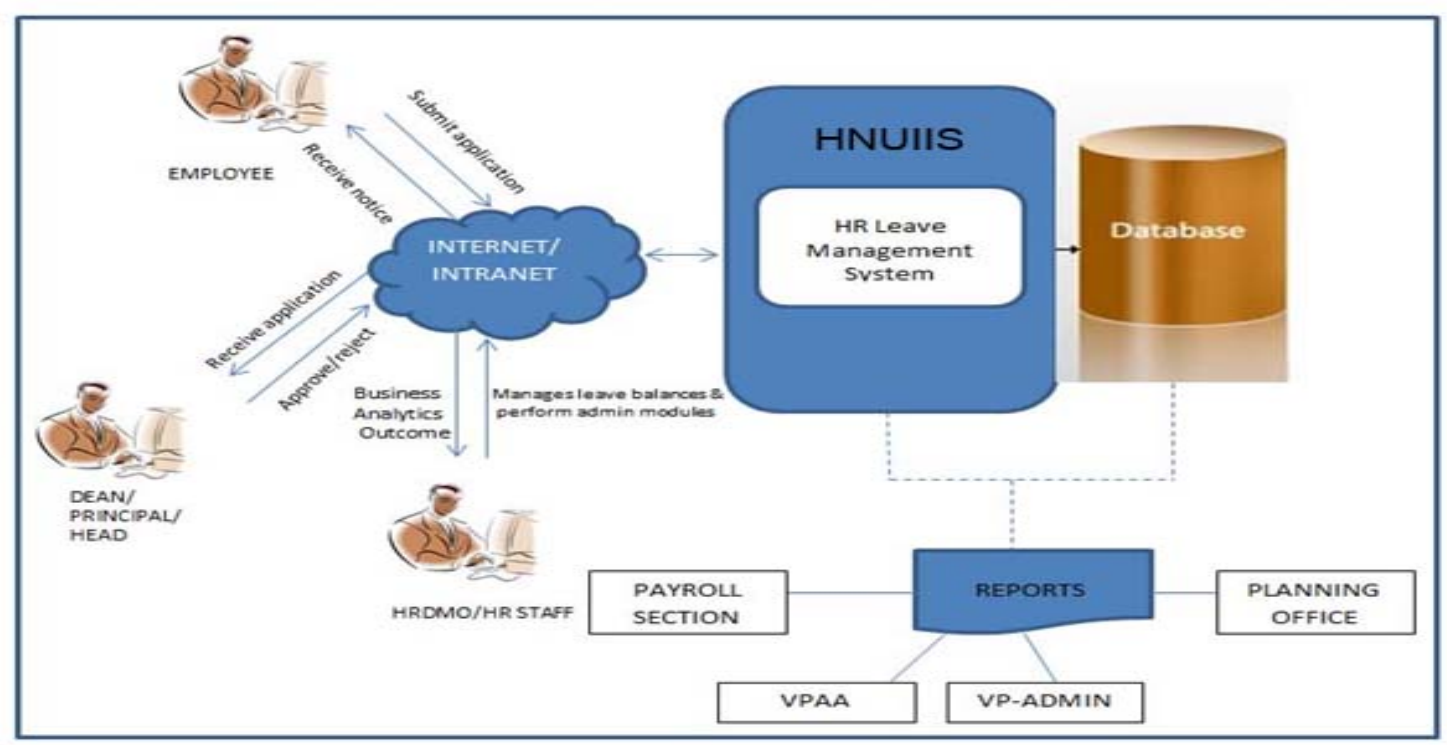

Figure 1. Development Diagram

\section{Development Methods}

Rapid Application Development has four essential aspects: methodology, people, management and tools. If any one of these ingredients is inadequate, development will not be high speed. Development lifecycles, which weave these ingredients together as effectively as possible, are of the utmost importance. The end-users had an active participation throughout the development process since the proponent constantly consulted them regarding the handling of the processes necessary for the management of the system. The development methods used were Process Modeling and UML diagrams. Process modeling involves geographically representing the functions, or processes, that capture, manipulate, store and distribute data between a system and its environment and between components within a system (Hoffer, Geroge \& Valacich, 2002).

\section{Analysis and Design Phase}

Analysis phase is the definition of the problem in the planning phase. It identifies the leave application online. The proponent used tools like pseudocode to outline the flow of how each of the process will be done. It was used in specifying the data inputs, processes and expected output requirements. The logical design is described using Unified Modeling Language (UML) and Entity-Relationship (ER) diagram. The results of the logical design are 
entities, attribute and the relationship of the entities within the database. It also describes the function of modules for each process within the database environment.

\section{Designing the Database}

There is already an existing HNUIIS of the school and the proposed system may be integrated to its HRDMO sub-system when it will already be developed by the MIS team, hence the proponent used the same structure and design as that of the existing system and accessed the needed distributed data in the existing database through the Federated Storage Engine introduced in MySQL 5.0. The federated storage engine of MySQL is extremely easy to use and set-up and can quickly answer demands to correlate data that exists on several different physical servers.

\section{UML Diagrams}

Unified Modeling Language (UML) has been used by IT professionals for the past decades. One of its purposes was to provide the development community with a stable and common design language that could be used to develop and build computer applications (Bell, 2003).

\section{Development Tools}

The project development was split into many areas and consists of: a) client side coding covering aspects such as the layout and design, b) server side coding which covers the website's functionality and back-end systems and c) the database.

\section{Client Side Coding.}

Ajax Asynchronous JavaScript enables web applications to send data to, and retrieve data from, a server asynchronously (in the background) without interfering with the display and behavior of the existing page (Ullman, 2007). This was helpful in the graphical display of the reports. Adobe Flash and Flash Player is a ubiquitous program and browser plugin that creates and views animation, vector graphics, audio, video and scripting (Adobe, n.d.). Minimal use of this was for the creation of menus, buttons and the prompt messages. JavaScript is a client side platform for creating and delivering rich web applications that can also run across a wide variety of devices (Mozilla Developer Network, n.d.). This was primarily used to validate forms in the website. This will also be used along with HTML5 to render graphs on the website. jQuery is a cross-browser JavaScript library designed to simplify and speed up the client-side scripting of HTML (jQuery Foundation, n.d.). HTML5 is a markup language for structuring and presenting content for the (WWC, 2011). This was used in the validation of forms in the website. CSS3 is a style sheet language used for describing the presentation semantics (the look and formatting) of a document written in HTML (W3C, n.d.).

\section{Server Side Coding}

PHP (Hypertext Preprocessor) is an open source server-side scripting language designed for web development (PHP Group, n.d.). This language has the ability to work with web forms and to communicate with databases.

\section{Database Technology}

MySQL is an open source relational database management system (RDBMS) that runs as a server providing multi-user access to a number of databases (MySQL AB, n.d.).

A solution stack such as XAMPP consists of the following: operating system (Linux, Windows, OSX), web server (Apache, IIS), database (MySQL, PostgreSQL) and the script language (PHP). XAMPP also provides support for creating and manipulating databases in MySQL and SQLite among others (Thakral, n.d.). 


\section{Development Environment}

The Eclipse Web Tools Platform (WTP) project is an extension of the Eclipse platform with tools for developing Web applications. It includes source and graphical editors for a variety of languages, wizards and built-in applications to simplify development, and tools and APIs to support deploying, running, and testing apps (Eclipse, n.d.). This was used by the proponent as this is free and open source software and it is capable of an automatic generation of documentations.

\section{Web Development Framework}

CodeIgniter is an open source rapid development web application framework for use in building dynamic web sites with PHP (CodeIgniter, n.d.). This framework is used by the HNUIIS team for its enrollment sub-system of the HNUIIS and so to avoid integration issues in the future, the proponent also used the framework.

\section{THE SYSTEM}

The main web page of the HRDM Officer account (Figure 2) allows the HRDM Officer, who is the super administrator of the system to manage employee, departments, leave types and leave credits records, manage leave applications and all transactions happening in the system and generates all the statistics and reports.

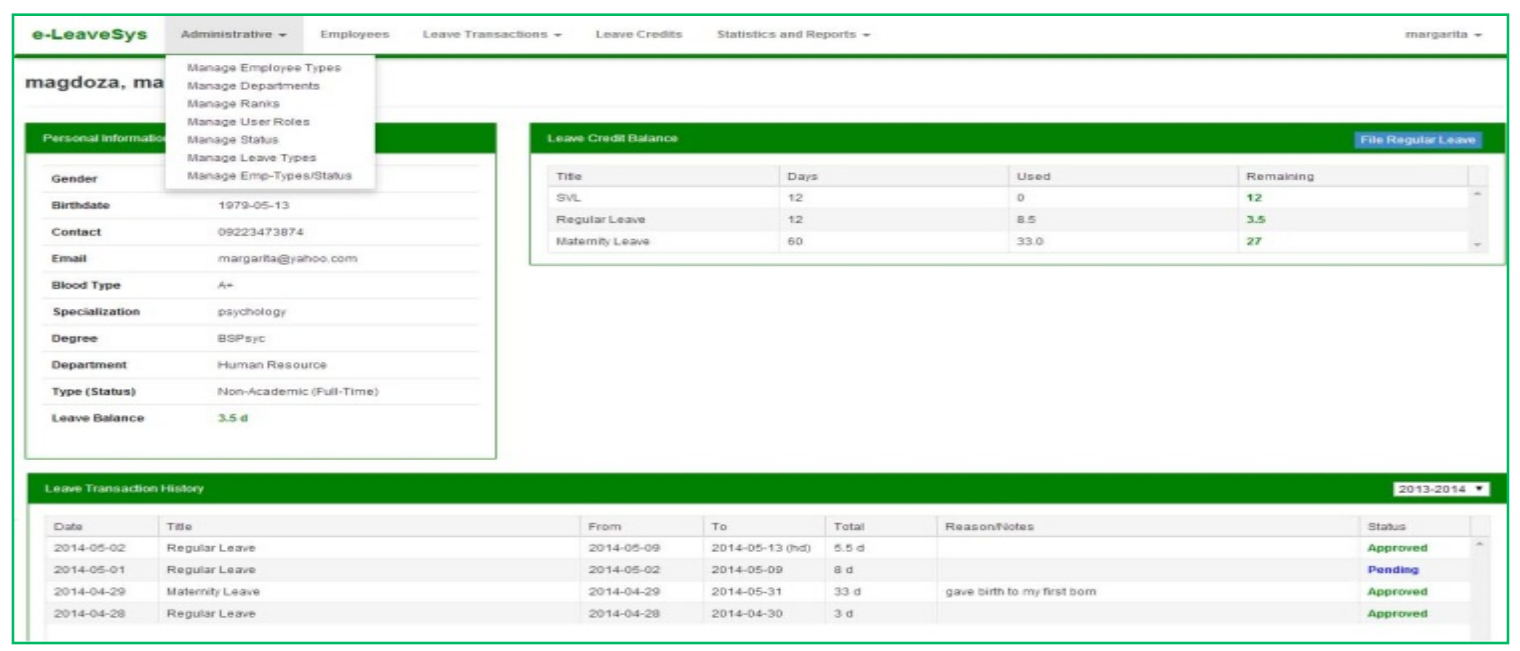

Figure 2. HRDM Officer Main Menu Options

\section{DECISION SUPPORT MECHANISM}

Decision-support systems (DSS) help the management and the HRDM Officer make more informed decisions. Business reporting or enterprise reporting will be used to extract, transform, and produce reports in human readable output that can be distributed in print form or viewed directly in the system. It will only involve data visualization like graphical reporting technique and customizable reports ready for printing in tabular and graphical format. This shall aid the HRDM Officer and the management in their strategic decision activities.

The HRDM Officer and the management can be assisted in their decision making activities with seven statistical reports both presented in tabular and graphical forms for each department or office: results of the Leave Trends of the Employees (Figure 3); the Employee Availability Reports; the Leave Rejection Report; the Employee Leave Balance Reports; the Leave Acceptance Report; the Employees with "No Leave in the Academic Year" Report ; and the Absence Monitoring Report. The Employee Availability and Absence Monitoring reports 
can also be viewed by the Principal/Dean/Head of Office. The Employee Leave Balance and Absence Monitoring reports can be viewed by the HR Staff.

All tabular reports are generated using the SQL queries. These reports are shown on a page by using tables so that the users can view the requested reports. For the graphical results, source data will be extracted using SQL queries from the database, appropriate computations are then done and the graphs will be generated using HTML5 and JavaScript. AJAX was used along with CSS to render the graphs on the website. All reports are converted into Portable Document Format (PDF) ready for printing.

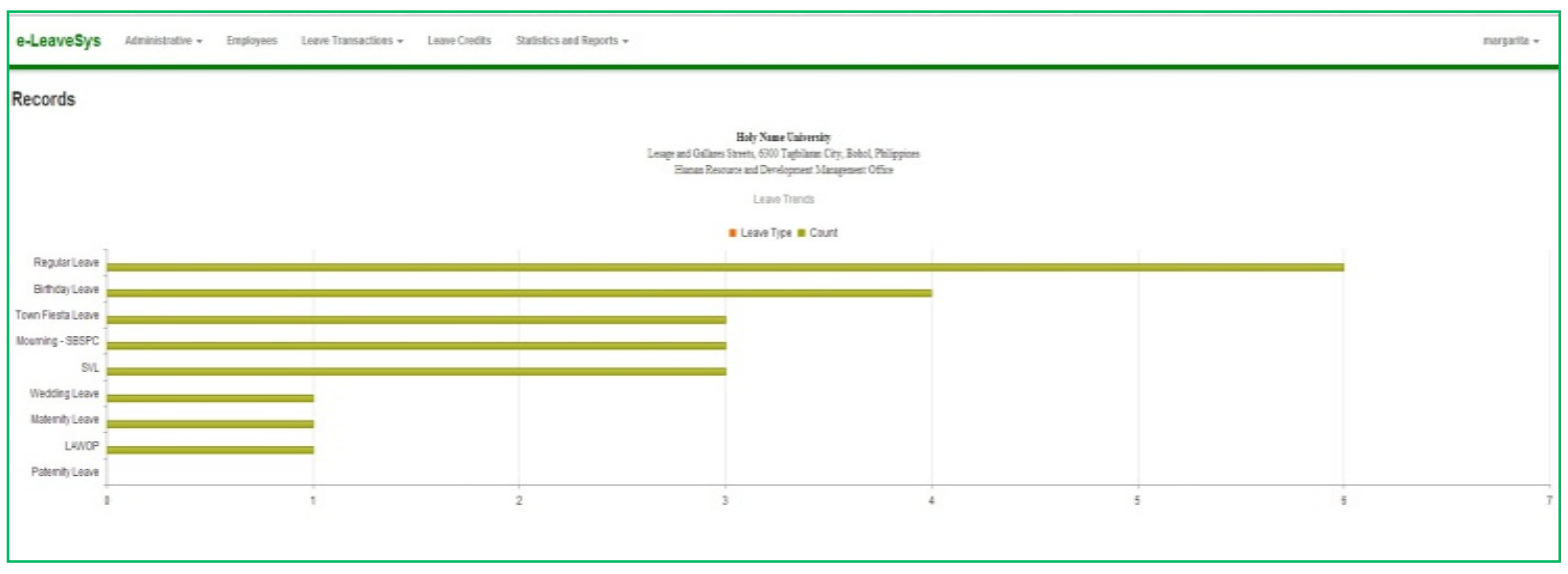

Figure 3. Leave Trends of the Employees

\section{TESTING AND EVALUATION}

\section{Usability}

The system usability that was participated in by the HRDM Officer and the two HR Staff, the proponent communicated to them the results of the preliminary survey conducted which helped solicit the problems as experienced by the employees with the present manual system and the proponent's desire to provide solutions to the identified problems. The System Usability Questionnaire that was used was based on Lewis (1995) IBM Computer Usability Satisfaction Questionnaires: Psychometric Evaluation and Instructions for Use.

Table 1. System Usability Result

\begin{tabular}{|l|c|c|}
\hline \multicolumn{1}{|c|}{ Criteria for System Usability } & $\overline{\mathbf{x}}$ & Description \\
\hline 1. Overall, I am satisfied with how easy it is to use this system. & 6.7 & Strongly Agree \\
\hline 2. It was simple to use this system. & 6.7 & Strongly Agree \\
\hline 3. I can effectively complete my work using this system. & 6.7 & Strongly Agree \\
\hline 4. I am able to complete my work quickly using this system. & 6.7 & Strongly Agree \\
\hline 5. I am able to efficiently complete my work using this system. & 6.3 & Agree \\
\hline 6. I feel comfortable using this system. & 6.7 & Strongly Agree \\
\hline 7. It was easy to learn to use this system. & 6.0 & Agree \\
\hline 8. I believe I became productive quickly using this system. & 6.3 & Agree \\
\hline $\begin{array}{l}\text { 9. The system gives error messages that clearly tell me how to fix } \\
\text { problems. }\end{array}$ & 6.0 & Agree \\
\hline $\begin{array}{l}\text { 10. Whenever I make a mistake using the system, I recover easily } \\
\text { \& quickly. }\end{array}$ & 6.0 & Agree \\
\hline $\begin{array}{l}\text { 11. The information (such as online help, on-screen messages, and } \\
\text { other documentation) provided by this system is clear. }\end{array}$ & 6.3 & Agree \\
\hline 12. It is easy to find the information I needed. & 6.7 & Strongly Agree \\
\hline 13. The information provided for the system is easy to understand. & 6.7 & Strongly Agree \\
\hline
\end{tabular}




\begin{tabular}{|l|c|c|}
\hline \multicolumn{1}{|c|}{ Criteria for System Usability } & $\overline{\mathbf{x}}$ & Description \\
\hline $\begin{array}{l}\text { 14. The information is effective in helping me complete the tasks \& } \\
\text { scenarios. }\end{array}$ & 6.7 & Strongly Agree \\
\hline 15. The organization of information on the system screens is clear. & 6.3 & Agree \\
\hline 16. The interface of this system is pleasant. & 6.3 & Agree \\
\hline 17. I like using the interface of this system. & 6.3 & Agree \\
\hline $\begin{array}{l}\text { 18. This system has all the functions and capabilities I expect it to } \\
\text { have. }\end{array}$ & 6.0 & Agree \\
\hline 19. Overall, I am satisfied with this system. & 6.3 & Agree \\
\hline AVERAGE WEIGHTED MEAN & 6.4 & Strongly Agree \\
\hline
\end{tabular}

The average weighted mean of the usability questionnaire is 6.4 which means - Strongly Agree. Based on the interpretations (Table 1), this implies that the respondents strongly believe and are confident that the system is very usable. The respondents also cited the things that they like most about the system software and it includes the very helpful prompt messages, its fullness with the necessary details that will guide the users throughout the whole process, its ease of use, its user-friendliness and most especially its being paperless. The HRDM Officer said that the fast and accurate preparation of reports can also help them immensely. They also commented that the system is very good and they like how it makes their tasks easier and how it will increase their productivity. They also mentioned about how the system could minimize conflicts with employees since evidence can now be recorded in the system in real time.

\section{Web Usability}

The Web Usability Survey consisted of questions that rate the website's aspects in Structure and Navigation, Labeling, Layout of the Page, Comprehensibility and Ease of Interaction, Control and Feedback and on General Aspects of the system. A total of 80 faculty, non-academic and ASP were randomly selected as respondents.

Table 3. Web Usability Results

\begin{tabular}{|l|c|c|c|c|c|}
\hline \multirow{2}{*}{ Indicators } & Faculty & ASP & Non-Ac & \multirow{2}{*}{ Description } \\
\cline { 2 - 4 } & $\overline{\mathbf{x}}$ & $\overline{\mathbf{x}}$ & $\overline{\mathbf{x}}$ & \multicolumn{1}{|c|}{ FC } \\
\hline General Aspects & 9.97 & 9.13 & 9.63 & 9.58 & FC \\
\hline Structure and Navigation & 9.97 & 9.38 & 9.48 & 9.61 & FC \\
\hline Labeling & 9.98 & 9.13 & 9.55 & 9.55 & FC \\
\hline Layout of the Page & 9.98 & 9.25 & 9.68 & 9.64 & FC \\
\hline $\begin{array}{l}\text { Comprehensibility and Ease of } \\
\text { Interaction }\end{array}$ & 9.97 & 9.50 & 9.84 & 9.77 & FC \\
\hline Control and Feedback & 9.98 & 9.33 & 9.66 & 9.66 & FC \\
\hline
\end{tabular}

FC means fully compliant

Based on the results (Table 3), the website showed full compliance $((\bar{x})=9.58)$, in General Aspects, full compliance $((\overline{\mathrm{x}})=9.61)$ in Structure and Navigation, full compliance $((\overline{\mathrm{x}})$ $=9.55)$ in Labeling, full compliance $((\overline{\mathrm{x}})=9.64)$ in Layout of the Page, full compliance $((\overline{\mathrm{x}})=$ 9.77) in Comprehensibility and Ease of Interaction and full compliance $((\overline{\mathrm{x}})=9.66)$ in Control and Feedback. The aggregate mean of 9.64 implies a very high result which means that the respondents decided that the website is fully compliant in all of the aforesaid aspects.

\section{Web Accessibility}

The researcher also submitted the completed system which is temporarily hosted at www.eleavesys.info to (http://wave.webaim.org/) for a free web accessibility evaluation. The website provides general procedures and tips for evaluation in different situations, from evaluation during website development to ongoing monitoring of existing sites for free. The tool examined the syntax and structure of the website and determined if the code follows Web 
Accessibility Guidelines. The proposed system's live site is error-free and successfully passed the Web Accessibility test.

\section{CONCLUSIONS AND RECOMMENDATIONS}

Based on the findings, it can be concluded that the proposed Human Resource e-Leave Management System will help make the whole leave management process of Holy Name University efficient. Users will be able to access the system from anywhere and anytime. This system will help the HRDM Officer and the management in decision making in case of leave related affairs. Moreover, it will ensure less paper work supporting the cost-cutting programs of the university. The Human Resource and Development Management Office (HRDMO) headed by the HRDM Officer and HR Staff will no longer be burdened by tasks associated with the implementation of complex leave management policies, including the completion and submission of leave application forms, verifying the eligibilities of the employees, preparation of reports, and other record-keeping transactions as these are already translated into automation and the system communicates to the user in terms of prompting of alert and error messages. The proposed system offers streamlined operations, fair application of paid leave policies, and the introduction of statistical reports lacking in the current manual system. It also brings about a more productive and empowered workforce as the Principal/Dean/Head of Offices are now given the authority to approve leave applications that makes the entire process more swift and effective.

Based on the conclusions, it is highly recommended that the proposed system should be integrated into the Holy Name University Integrated Information System (HNUIIS). For a successful implementation of the proposed system, the following recommendations should be well taken:

It is highly recommended that the proposed system should be integrated to the Holy Name University Integrated Information System (HNUIIS) so that the process of leave management will be automated. Second, to implement the streamlined processes of the various leave management tasks and incorporate the new processes such as automatic tracking and management of leave policies in real time and the generation of up-to-date reports and invaluable summary data to support the HRDM Officer and the Management in their decision making activities. Third, there must be an intensive hands-on training of all the users of the system to ensure that the system's capabilities and features will be well-understood and properly utilized. Fourth, a parallel run for the implementation of the system will be conducted for a semester to ensure that all transactions are properly managed and are already stable before discarding the old manual ways. An evaluation of the system must be conducted periodically for further improvement and development. Lastly, it must be included in the Policy Statement that the Head of Office must see to it that they check the system or their email accounts from time to time to be able to respond to the leave applications submitted by their subordinates in a timely manner.

\section{ACKNOWLEDGMENTS}

This project would not have been possible without the help of the Human Resource Development and Management Office (HRDMO) particularly its Human Resource Development Program, its Officer and Staff and to the employees of Holy Name University who were the respondents in any respect during the completion of the project. Also, to its Human Resource Development Program for the partial scholarship granted to the principal author. Further, we would like also to recognize the 12th National Conference on Information Technology Education (NCITE 2014) for the comments and suggestions in improving this article. 


\section{REFERENCES}

Adobe. (n.d.). Flash Player Download Center. Retrieved April 10, 2012 from Get.adobe.com.

Bell, D. (2003). UML Basics: An Introduction to the Unified Modeling Language. Technical Library.

CodeIgniter (n.d.). CodeIgniter User Guide : CodeIgniter at a Glance. Retrieved 2009-07-24 from http://www.codeigniter.com/user_guide/overview/at_a_glance.html

Developer Mozilla Network. (n.d.). New in JavaScript 1.8.5. Retrieved 2013-05-26 from Developer.mozilla.org.

Eclipse (n.d.). Eclipse Web Tools Platform Project. Retrieved May 2, 2013 from http://projects.eclipse.org/projects/webtools

Heathfield, S. M. (n.d.) What Is Human Resource Management?. Retrieved July 2,2013 from http://humanresources.about.com/od/glossaryh/f/hr management.htm;

Hoffer, J. A., Geroge, J. F. \& Valacich, J. S. (2002). Modern System Analysis and Design. Ed. 3rd. Pearson Education (Singapore) Pte. Ltd.:India

Jayarathna, A. (n.d.) Feasibility Study Report Personal. Retrieved July 9, 2013 from http://www.slideshare.net/akila712712/feasibility-study-report-personal-information-leavemanagement-system.

jQuery Foundation. (n.d.). License - jQuery Project. Retrieved 5 January 2013 from https://jquery.org/license/.

MySQL AB. (n.d.). History of MySQL. MySQL 5.1 Reference Manual. Retrieved 26 August 2011 from https://dev.mysql.com/doc/refman/5.1/en/history.html

Shepherd University (n.d.) Shepherd University’s Leave Management System. Retrieved July 3, 2013 from https://login.replicon.com.

Thakral, R. (n.d.). What is XAMPP?. Retrieved July 9, 2013 from www.knowledgement.ie/technical/programming/what-is-xampp.

The PHP Group. (n.d.). History of PHP and related projects. Retrieved 2008-02-25 from http://php.net/manual/en/history.php

University of Technology, Retrieved June $23, \quad 2013$ from https://www.utech.edu.jm/lmis/Account/Login.aspx?ReturnUrl=\%2flmis\%2fDefault.aspx.

University of San Carlos, Retrieved July 5, 2013 from www.beta.usc.edu.ph.

Ullman, C., Dykes, L. (March 2007). Beginning Ajax. Wrox.

World Wide Web Consortium (April 5, 2011) HTML5 Differences from HTML4. Working Draft. Retrieved from http://www.w3.org/TR/html5-diff/.

World Wide Web Consortium. (n.d.). What is CSS?. Retrieved December 2010 from http://www.w3.org/standards/webdesign/htmlcss\#whatcss 